\title{
O campo de estudos socioantropológicos sobre diversidade sexual e de gênero no Brasil: ensaio sobre sujeitos, temas e abordagens*
}

\author{
Júlio Assis Simões** \\ Sérgio Carrara***
}

\section{Resumo}

Este ensaio busca contribuir para a análise do campo de estudos socioantropológicos sobre diversidade sexual e de gênero no Brasil. Nele, são mapeadas questões e abordagens que ganharam destaque na conformação mais recente desse campo, marcado pela crítica à "homossexualidade" como categoria classificatória e identidade social englobante. Interessa-nos apontar alguns problemas de ordem conceitual e metodológica que têm se erguido como desafios aos pesquisadores, em um contexto de extraordinária multiplicação do número de investigações sobre sexualidade e gênero, bem como de crescente politização desses temas.

Palavras-chave: Homossexualidade, Diversidade Sexual e de Gênero,Pesquisa Socioantropológica, Brasil.

* Recebido para publicação em 20 de fevereiro de 2014, aceito em 26 de maio de 2014.

** Professor do Departamento de Antropologia da USP. juliosimoes@usp.br

*** Professor do Departamento de Políticas e Instituições de Saúde do IMSUERJ. carrara@ims.uerj.br 
The Field of Socio-Anthropological Studies on Sexual and Gender Diversity in Brazil: an Essay on Subjects, Themes and Approaches

\begin{abstract}
This essay seeks to contribute to the analysis of the field of socioanthropological studies on sexual and gender diversity in Brazil. It maps issues and approaches that were highlighted in the latest conformation of this field, marked by the critics of "homosexuality' as an encompassing classificatory category and social identity. We are interested in pointing out some conceptual and methodological issues that have been raised as challenges in the context of an extraordinary increase of research on sexuality and gender, as well as increasing politicization of these topics.
\end{abstract}

Key Words: Homosexuality, Sexual and Gender Diversity, Socialanthropological Studies, Brazil. 


\section{Introdução: um campo cambiante e contestado}

O presente artigo busca contribuir para a análise do campo de estudos socioantropológicos sobre "homossexualidade" no Brasil. Tomamos como ponto de partida os debates que, desde 2004, vêm acontecendo no âmbito dos Encontros Anuais da Associação Nacional de Pós-Graduação e Pesquisa em Ciências Sociais - ANPOCS, por meio de um grupo de trabalho sobre sexualidade e gênero que, com diferentes denominações, tem se constituído em fórum regular de discussão da temática na perspectiva das ciências sociais.

Não se trata aqui de fazer um balanço geral do conjunto rico e diversificado de trabalhos propostos e apresentados ao grupo. Mapearemos apenas questões e abordagens que ganharam destaque na conformação do campo de estudos sobre o que vem sendo atualmente denominado como "diversidade sexual e de gênero", "sexualidades e expressões de gênero dissidentes" ou "não convencionais", "não normativas" e "não hegemônicas", conforme as diferentes perspectivas adotadas pelos pesquisadores. Alertamos de antemão que, assim como "homossexualidade" termo que no passado conferia unidade ao campo e que há mais de uma década está envolvido em um processo de contínua especificação, disputa e contestação - nenhuma dessas novas designações recobre plenamente o objeto em torno do qual têm girado preocupações e análises.

Ao efetuar esse mapeamento propositalmente seletivo, interessa-nos apontar alguns problemas de ordem conceitual $e$ metodológica que têm se erguido como desafios, notadamente na antropologia, disciplina que se destaca pela quantidade $e$ qualidade de trabalhos produzidos sobre sexualidade entre nós. Não é demais lembrar que vivemos, com efeito, um período bastante fértil e produtivo para a investigação socioantropológica sobre sexualidade. Desde 2004, quando a proposta de um grupo de trabalho sobre o tema foi acolhida no Encontro Anual da ANPOCS, no formato de seminário temático (então denominado "Corpo, sexualidade e identidade"), até o presente, a sexualidade 
parece ter alcançado um novo patamar de interesse e legitimação como objeto próprio de investigação nas ciências sociais, ganhando crescente autonomia em relação a questões e recortes referentes à saúde ou à demografia.

O grupo de trabalho instituído na ANPOCS teve um papel importante nesse sentido, seja como articulador da produção que se desenvolvia nos centros de pós-graduação e pesquisa já estabelecidos, seja como incentivador da formação ou do revigoramento de outros fóruns de discussão similares, no âmbito de congressos e reuniões de antropologia e sociologia de alcances nacional e regional. Além disso, tem estimulado a criação de linhas de pesquisa em sexualidade em outros centros e programas nas áreas de ciências sociais no país. Explorando um arco de aspectos proeminentes $e$ interligados na abordagem da sexualidade - valores, práticas, saberes, moralidades, políticas - $e$ fomentando a discussão das implicações éticas e metodológicas dos processos de pesquisa e escrita sobre o tema sob os mais diversos recortes (para além do que aqui delimitamos como o campo que antes correspondia às "homossexualidades"), o grupo tem contribuído para iluminar e aprimorar a compreensão das múltiplas dimensões associadas à própria noção de sexualidade. ${ }^{1}$

Certamente, esse relativo e recente sucesso dos estudos socioantropológicos sobre sexualidade no Brasil - e das "sexualidades e expressões de gênero não normativas", em particular - vincula-se também à crescente autonomização da sexualidade como um plano relevante de exercício de direitos, em que se constituem novos atores políticos, cujas identidades coletivas são forjadas em torno de formas específicas de desejos,

\footnotetext{
1 Nesse sentido, a sexualidade é compreendida por nós, aqui, não apenas como o dispositivo foucaultiano (Foucault, 2001), mas também como o que poderíamos chamar de habitus erótico; ou seja, conjunto de princípios estruturantes de práticas e discursos, mas também de sensações, desejos, atrações, emoções, representações, que definem, sob diferentes circunstâncias, as fronteiras entre o que é sexualmente desejável e o que é indesejável, o que é respeitado e o que é vergonhoso.
} 
de práticas sexuais e de performances ou "expressões" de gênero. Trata-se do processo mais geral de emergência dos "direitos sexuais" como direitos humanos; e, em particular, seus desdobramentos como direitos que se referem a prerrogativas às quais determinadas pessoas e grupos sociais não teriam acesso por estarem submetidos a formas de discriminação social e política por conta de suas "sexualidades" e/ou "expressões de gênero".

É nesses termos que podemos situar a emergência dos chamados "direitos da diversidade sexual e de gênero" e, num recorte ainda mais particularizante, dos "direitos LGBT". O ano de 2004 pode novamente ser invocado por marcar o lançamento do programa governamental Brasil Sem Homofobia, destinado a

\begin{abstract}
promover a cidadania de gays e lésbicas, travestis, transgêneros e bissexuais, a partir da equiparação de direitos $e$ do combate à violência $e$ à discriminação homofóbicas, respeitando a especificidade de cada um desses grupos populacionais (Brasil, 2004).
\end{abstract}

Nessa formulação oficial, de uma década atrás, podemos reconhecer o elenco cambiante de categorias identitárias que se afirmam no plano político através de siglas igualmente cambiantes, sendo "LGBT" a que se mantém no momento em que escrevemos. ${ }^{2}$ Também se tornam visíveis as variadas combinações entre aparência corporal, identificações de gênero e orientações sexuais decorrentes da fragmentação da "homossexualidade" como categoria classificatória e identidade social. É a contrapartida teórica desse processo político, levando à explosão do campo de estudos da "homossexualidade", que nos interessa examinar.

Ressalte-se ainda que antropólogos e antropólogas que estudaram o tema participaram ativamente na arena política, interferindo na constituição de seu objeto e nas transformações

2 Sobre o movimento LGBT e a formação de um campo de "direitos LGBT" no Brasil, ver, entre outros, Facchini, 2005; Simões e Facchini, 2009; Aguião, 2014. 
pelas quais ele passou nas últimas décadas. A antropologia está profundamente implicada no processo mais amplo de "cidadanização" das "sexualidades e expressões de gênero nãonormativas" (Carrara, 2013), e disso decorrem importantes questões teóricas e epistemológicas. A competência específica da antropologia para a coleta e o registro de experiências sociais, sustentada na "comunicação simbólica que supõe e repõe processos básicos responsáveis pela criação de significados e de grupos" (Cardoso, 2011:218), torna-a especialmente afeita e sensível ao complexo de interações e transações que viabilizam o trabalho de investigação científica, com evidentes implicações políticas. Nesse espaço de intenso tráfico de pessoas, ideias, linguagens, preocupações e, principalmente, de legitimação mútua, os pontos de vista dos múltiplos atores sociais que participam dessa teia de negociações e compromissos incorporamse, de um modo ou de outro, nos fatos produzidos e configuram o discurso sobre eles.

Essas questões, ligadas à politização dos temas e dos próprios métodos de trabalho da antropologia, tornam-se mais cruciais quando envolvem pessoas e populações tidas como marginais, estigmatizadas e subalternas em busca de reconhecimento e protagonismo político. Não são, portanto, exclusivas dos estudos antropológicos sobre "sexualidades $e$ expressões de gênero nãonormativas", nem mesmo são uma singularidade do momento presente. ${ }^{3}$ Realçá-las aqui não implica nenhum demérito à disciplina ou à temática, que ambos cultivamos. Trata-se, antes, de não ocultar o diálogo complexo e multifacetado a partir do qual esse conhecimento é produzido, tendo sempre em perspectiva as razões sociais e políticas que o

${ }^{3}$ Nesse sentido, podemos evocar aqui a reflexão crítica de Eunice Durham, escrita há quase trinta anos, sobre a produção brasileira em antropologia urbana, em que discutia o modo como a antropologia de então "contornava" os problemas decorrentes da politização dos temas que tratava, ao mesmo tempo em que era imprecisa em relação à própria posição política do pesquisador (Durham, 2004). 
tornam importante, de modo a, ao menos, evitaras armadilhas de certa ingenuidade objetivista.

\section{Duas grandes fraturas}

Partimos do suposto de que o campo de estudos socioantropológicos sobre as sexualidades e expressões de gênero não normativas foi em larga medida construído sobre os poucos estudos que, até meados dos anos 1990, a antropologia brasileira havia produzido sobre a "homossexualidade" ${ }^{4}$ - ou seja, sobre um tema ou objeto que a disciplina herdara da psiquiatria e da medicina legal. Do ponto de vista de seus principais autores, uma sucinta genealogia do que foi feito até o início dos anos 2000 deveria começar com Ruth Landes (2002 [1947]) e passar por José Fábio Barbosa da Silva (2005 [1958]), René Ribeiro (1978 [1969]), Seth e Ruth Leacock (1972), Carmen Dora Guimarães (2004 [1977]), Rosemary Lobert (2010 [1979]), Peter Fry (1982a [1974], 1982b [1977]), Luiz Mott (1982a, 1982b), Peter Fry e Edward MacRae (1983), Edward MacRae (1990), Nestor Perlongher (1987), Richard Parker (1991 [1988]), Maria Luiza Heilborn (2004 [1992]), Hélio Silva (1993), entre outros. Com a progressiva consolidação desse campo de estudos, a eles viria se agregar, ao longo da década de 1990 e sobretudo a partir dos anos 2000, um conjunto muito mais amplo de pesquisadores, entre os quais nós mesmos nos situamos.

Do ponto de vista da própria definição de seu objeto, o campo de estudo das "homossexualidades" sofreu duas grandes fraturas que conduziram à explosão de sujeitos, temas $e$ abordagens que hoje o caracteriza. Em relação a uma possível história política e epistemológica, esses dois grandes divisores poderiam ser chamados de "a emergência gay-lésbica", que ocorre entre os anos 1970 e 1980, e "a emergência trans", que situaríamos na passagem do milênio. Não é demais lembrar que o contexto do primeiro divisor é o da configuração de uma linhagem

${ }^{4}$ Para uma análise de parte dessa produção, ver Carrara e Simões, 2007. 
de estudos que tomaram como objeto principalmente a homossexualidade masculina, sendo simultâneo à própria emergência do "movimento homossexual brasileiro"; ao passo que o segundo corresponde ao momento de nossa própria experiência de pesquisa, quando também se dá simultaneamente a produção de um campo de "direitos LGBT".

No Brasil, sobretudo a partir dos anos 1980, "homens homossexuais", muitos já autoidentificados como "gays", rompiam com as expectativas de feminilidade que de modo geral recaíam sobre eles, afirmando de diferentes maneiras que não era porque se sentiam sexualmente atraídos por pessoas do mesmo gênero/sexo que se identificavam com o sexo/gênero oposto. Menos visível socialmente, o mesmo processo ocorria com "mulheres homossexuais/lésbicas". ${ }^{5}$ Tornava-se concebível e até mesmo desejável que parcerias homossexuais envolvessem homens igualmente viris e mulheres igualmente femininas, ou parceiros que pudessem alternativamente ocupar posições ou performances masculinas e femininas sem se fixar em nenhuma delas. Trata-se da emergência plena do que Peter Fry chamou de "modelo igualitário", cujo domínio sobre modelos concorrentes, também presentes na sociedade brasileira, tanto preocupava o antropólogo no início dos anos 1980.

No caso da homossexualidade masculina, ao afirmarem essa primeira disjunção entre sexualidade e expressões de gênero, "gays" separavam-se de "travestis" e "transexuais", negando uma "natureza" ou "condição" comum. Iniciava-se aqui o regime da gaycidade, como o sociólogo argentino Ernesto Meccia (2011) o chamou muito apropriadamente ${ }^{6}$ e que poderia ser

5 Vale lembrar que as pesquisas sobre lésbicas nos Brasil começam a surgir um pouco mais tarde, a partir da virada dos anos 1980 para 1990 (por exemplo, Portinari, 1989; Aquino, 1992; Muniz, 1992; Heilborn, 2004). Embora tenham aumentado nos anos 2000, continuam a ser em menor número do que os estudos dedicados a homossexuais masculinos.

6 Cabe ressaltar que Meccia trabalha propositalmente com um enquadramento sociológico de amplo alcance. A aplicação de seu esquema analítico para outros coletivos envolvidos em dinâmicas de discriminação e reconhecimento - mesmo 
resumidamente descrito a partir (i) do surgimento da organização política de homossexuais, gays e lésbicas; (ii) da simultânea construção de uma coletividade marcada pela luta contra a discriminação e o preconceito; (iii) da extensão de redes de sociabilidade homossexual para além do gueto (visibilidade social), e (iv) da consequente organização de um mercado de estilos e lugares de consumo, segmentado segundo linhas de classe e geração.

Em uma relação especular ao primeiro divisor, o segundo se dá a partir da crescente organização política de travestis e de homens e mulheres transexuais, que marca a passagem do milênio. Como havia acontecido anteriormente no caso de gays $e$ lésbicas, tais sujeitos passam a articular um discurso público alternativo àquele que, muitas vezes em seu nome ou supostamente em seu favor, vinha sendo feito sobre eles. Embora com consequências sociais e simbólicas distintas da emergência gay-lésbica, a emergência trans faz afirmação semelhante, mas em sentido contrário. Tudo se passa como se dissessem: não é pelo fato de nos identificarmos com o gênero/sexo oposto que nos sentimos invariavelmente atraídos ou atraídas por pessoas do mesmo sexo/gênero.

É a partir dessa dupla ruptura e das ondas de choque que liberou que se institui o campo contemporâneo de reflexão em que nos situamos. Tal campo se constrói sobre as ruínas da homossexualidade, conceito que por um século unificou "sexualidade e expressóes de gênero não normativas" em uma totalidade mais ou menos coerente.

Em suas várias camadas de sentido, seus diversos sujeitos e temáticas, essa história curta, mas acidentada, está impressa no próprio grupo temático sobre sexualidade da ANPOCS; tanto em

dentro do arco "LGBT", além dos homens gays - certamente requer contextualizações e ponderações que não poderão ser tratadas aqui. No caso das lésbicas, por exemplo, seria preciso levar em conta a menor dimensão e menor visibilidade dos espaços de sociabilidade, bem como outras singularidades nos trânsitos entre discrição e reivindicação identitária. 
sua concepção, quanto no conjunto de propostas que foram enviadas aos coordenadores ao longo de quase uma década. Tomaremos como referência aqui apenas as propostas encaminhadas no período mais recente, entre 2009 e 2012, e nos concentraremos exclusivamente na parcela que trata de "diversidade sexual de gênero". Dentre os 245 resumos propostos nesses quatro anos, 105 (43\%) referiam-se à temática da "diversidade sexual e de gênero". Trata-se de um número expressivo que demonstra o fato de o grupo ter se constituído em espaço importante para a discussão de questões em torno das quais, atualmente, multiplicam-se projetos e linhas de pesquisa em diferentes universidades brasileiras. Se é inegável que houve um notável crescimento da produção socioantropológica sobre sexualidade ao longo da última década, focalizar período mais recente pode ser estratégico para começarmos a formar uma percepção mais acurada a respeito do que essas pesquisas emergentes sinalizam. Desse modo, iremos abordá-lo com o objetivo de esboçar um painel preliminar dos sujeitos que nele se expressaram, e a partir daí tecer alguns comentários adicionais sobre temas e abordagens. ${ }^{7}$

\section{Sujeitos}

Um dos efeitos mais notáveis da dupla disjunção entre sexualidade e gênero operada pela emergência gay-lésbica e pela emergência trans foi a proliferação de inúmeras "sexualidades" $e$

\footnotetext{
7 Todos os termos e expressões mencionados entre aspas nos parágrafos a seguir, foram extraídos do conjunto de resumos que selecionamos para compor o painel de sujeitos, temas e abordagens, a partir do qual ensaiamos essa reflexão crítica. Não citamos os resumos individualmente, com referência a seus títulos, autores e datas de apresentação, não apenas porque foram em número considerável (mais de 100), mas principalmente porque não é o caso, aqui, de avaliar suas possíveis contribuições teóricas e/ou empíricas (o que, de resto, nem sequer poderia ser feito adequadamente, em se tratando de resumos). Nosso propósito é situar tendências e perspectivas mais amplas, detectáveis nesse conjunto ilustrativo da produção recente.
} 
"identificações de gêneros". ${ }^{8}$ Quanto às identidades pessoais $e$ coletivas que se articularam a partir de tais sexualidades $e$ identificações, as que foram mencionados no GT comportam: "homossexuais", "homens e mulheres homossexuais", "homoeróticos", "homoafetivos", "MSM", "HSH", "mulheres que fazem sexo com mulheres", "mulheres que possuem práticas homoeróticas", "homens que fazem sexo com homens", "homens que mantêm práticas afetivo-sexuais com outros homens", "homens que se relacionam afetivo/sexualmente com outros homens", "homens que "praticam crossdressing", "mulheres que se identificam com um "jeito de ser masculino", "gays", "lésbicas", "bissexuais", "travestis", "transexuais", "transgêneros", "crossdressers" e "transformistas".

Como resultado de uma análise ainda preliminar, as categorias mobilizadas nos resumos apresentados poderiam ser dispostas em pelo menos quatro eixos. O primeiro continua a se articular em torno da noção de homossexualidade $e$ incluiria menções a sujeitos designados como "homossexuais", o que invariavelmente se refere apenas a homens ou "homossexuais masculinos" (temos apenas duas menções à "homossexualidade feminina"), "homoeróticos" e "homoafetivos". No segundo eixo, estariam situadas categorias mais singularizadas, como "gay", "lésbica", "bissexual", "transgênero", "transexual", "travesti", "transformista", "dragqueen", "crossdresser", "queer". O terceiro reúne expressões que, embora façam referência a identidades singulares, aparecem na forma de siglas como "LGBT" ou "GLBTTT", de conotação mais política. No quarto, finalmente, temos termos e expressões que buscam designar sujeitos a partir de práticas; alguns aparecendo também na forma de siglas, como "HSH" (homens que fazem sexo com homens) e "MSM" (mulheres que fazem sexo com mulheres); e outros, a partir de descrições

${ }^{8}$ Facchini et alii (2013) notam que a segunda metade dos anos 2000 é justamente o período em que crescem estudos sobre práticas sexuais, abordadas sem referência a dicotomias mais englobantes, como hetero-homossexualidade ou masculino-feminino. 
mais longas, como acontece, por exemplo, em "mulheres que possuem práticas homoeróticas".

Alguns desses sujeitos mereceram atenção especial. É incomparavelmente maior o número de trabalhos que mencionam "travestis" (34), "homossexuais" (27) e "gays" (21) - os termos mais utilizados - quando comparados aos que mencionam "lésbicas" (7), "homoeróticos" (7), ou "bissexuais" (apenas 1).

É importante insistir que todos esses termos classificam ou denominam pessoas ou conjuntos de pessoas, sejam os que fazem referência explícita a designações identitárias, sejam os que se referem a certas modalidades de desejo ou práticas sexuais. Algumas dessas classificações são mais presentes na linguagem cotidiana, como "homossexuais", "lésbicas" ou "travestis". Outras aparecem em formulações bem mais enigmáticas, como "sujeitos homoeróticos", "pessoas LGBT" ou mais simplesmente os "LGBTs" ou os "LGBT's brasileiros" (com o curioso apóstrofo), os "HSHs", as "MSMs", ou ainda "indivíduos que compartilham uma identificação queer".

Essas mesmas expressões aparecem também para adjetivar um sem número de referentes com distintos graus de materialidade ou com estatutos ontológicos diversos. Tais referentes vão desde os mais concretos - como locais de diversão e consumo ("discotecas gays"), ou histórias em quadrinhos ("hds japonesas homoafetivas"); passam pelos que são apenas observáveis - como eventos políticos e sociais (paradas, festas) ou "relações", "práticas", "interações", "condutas", "comportamentos", "sociabilidade"; "movimento", "militância"; e chegam aos mais subjetivos - como "experiências", "desejos", "afetos" e abstratos - como "estilo de vida gay", "olhar transgênero" ou "temporalidade queer".

Podemos dizer que tais termos classificatórios são de modo geral pouco problematizados, apesar das ressalvas feitas em alguns casos; e operam como uma espécie de atalho para designar o conjunto de pessoas envolvidas nas diferentes pesquisas, sem corresponder muitas vezes ao modo como essas pessoas designam a si próprias. Isso não significa dizer que haja uma completa 
naturalização de identidades e categorias sociais. Em muitos momentos, esses termos aparecem entre as devidas aspas, apontando para o fato de que se trata de categorias classificatórias.

Não parece haver também consenso sobre como abordar esse conjunto de identidades múltiplas, quando passam a designar fenômenos de morfologia ou estratificação social. Nesse caso, elas são tratadas ora como "população" (como em "população de mulheres que fazem sexo com mulheres/MSM", "população LGBT", "população travesti") ou "público" ("público homossexual"); ora como "grupo" ("grupos com orientação homossexual"), "sociedade" ("sociedade secreta de homossexuais"), "segmento" ("segmento LGBT") ou "coletivos" (como em "coletivos sexuais"). Em certos casos, compõem "universos" (como em "universo homoerótico"), "cenas" (como em "cena gay"), "campos" (como em "campo LGBT") ou mercados (que geralmente aparece em relação à sigla GLS - "gays, lésbicas e simpatizantes"). Resta ainda por ser feita uma discussão mais aprofundada sobre o estatuto sociológico dessas coletividades ou, ao menos, sobre como poderiam ser sociologicamente tratadas segundo diferentes contextos.

\section{Temas e abordagens}

É possivel observar também a incidência diferencial de certos sujeitos, segundo os temas abordados. A única referência a "bissexuais", por exemplo, aparece em um trabalho que discute o poliamorismo. A referência a "travestis" predomina quando o assunto é prostituição (no período considerado não encontramos trabalhos abordando o tema da prostituição viril); assim como quando os interesses se voltam para performances $e$ corporalidades, sobretudo para modificações corporais. Já "homossexuais", "homoeróticos" e "gays" prevalecem quando se trata de sociabilidade. Esse é, aliás, o tema que forma o conjunto numericamente mais expressivo de trabalhos apresentados ao longo desses dez anos.

A noção de sociabilidade empregada nos trabalhos parece recobrir aquilo que Georg Simmel denominou de "formas 
autônomas ou lúdicas de sociação" (embora o próprio Simmel não seja muito citado) - "estar com outro, para um outro, contra um outro" - caracterizadas pelo sentimento de estar junto e pela satisfação derivada de provocar efeitos nos outros ou de receber esses efeitos (Simmel, 1983:168). Nas colaborações ao GT, tais formas são capturadas em lugares de encontro, lazer, paquera, "pegação" e interações eróticas, que compõem, como já dito, cenas e universos diversificados; sendo que o sentido $e$ o alcance de todos esses termos parecem variar conforme os recortes de cada pesquisa.

É interessante notar que raramente esses recortes incluem as relações que esses sujeitos mantêm com pessoas fora do círculo de iguais, em contextos mais amplos de suas vidas - com amigos, familiares ou mesmo com cônjuges ou algum outro status de relacionamento, para utilizar uma expressão que tem sido muito divulgada com o advento, na internet, de sites como o facebook. Ainda que tais relações possam ser evocadas pelas pessoas pesquisadas, é raro que se convertam no foco de pesquisa. Com efeito, no período selecionado encontramos apenas um trabalho sobre "esposas de crossdressers" e um sobre "mães de gays".

As pesquisas sobre sociabilidade tendem a dar ênfase às práticas e expressões de corpos - em termos que às vezes lembram as "materializações corporais" de Judith Butler (1993) - referidas a sujeitos designados de formas múltiplas. Essa preocupação com as diferentes expressões dos corpos ou corporalidades tendeu crescentemente a pleitear noções de "marcadores sociais da diferença" e "interseccionalidades". Mas (tal como também acontece com Butler) em muitos trabalhos a articulação privilegiada é a que se dá entre corpo, sexualidade e gênero.

Ainda em relação a marcadores de diferença, notamos um número crescente de trabalhos que exploram articulações entre corpo/sexualidade/gênero e idade/geração, privilegiando, sobretudo, a adolescência e o envelhecimento - curiosamente, mais o envelhecimento do que a adolescência. Esses trabalhos lidam quase exclusivamente com "gays" ou "homens homossexuais", e 
um novo conjunto de categorias decorre desse recorte, como "coroas", "tios", "tiozões", "velhos", "idosos", "maduros". Como parte deles se inclui na coorte geracional de onde provieram os antigos "entendidos" (espécie de categoria fóssil, uma vez que não aparece em nenhum dos trabalhos propostos ao grupo), ou os primeiros gays, não admira, que a categoria "gay" pareça estar envelhecendo junto com os sujeitos que designa.

Em contrapartida, as articulações que envolvem marcadores de raça e classe, embora frequentemente anunciadas, parecem constituir o cerne de um conjunto ainda reduzido de pesquisas. Em suas realizações talvez mais proveitosas, as pesquisas feitas sob esse enfoque têm permitido problematizar as hierarquias $e$ assimetrias em alguns sentidos importantes, eventualmente sugerindo uma mecânica de poder que produz tanto efeitos de exclusão quanto possibilidades de agência. Muitas vezes, porém, a anunciada preocupação com as "interseccionalidades" limita-se a uma proclamação que não se cumpre. Classe (com 7 menções) e raça (com apenas 3) são, nesse sentido, vestigiais e as articulações entre sexualidade, classe e raça são mais referidas como intenções do que analisadas em profundidade.

Além das "interseccionalidades", outra referência nova em termos de abordagem são os chamados estudos queer. Quando referido como um tipo específico abordagem, queer quase sempre aparece precedido da palavra "teoria", às vezes em caixa alta. $\mathrm{O}$ termo queer parece ter se popularizado principalmente como uma maneira nova de se referir a antigos problemas relacionados às potencialidades e limitações da política de identidades. Sob esse aspecto, denuncia-se o aprisionamento identitário (mesmo na forma do "essencialismo estratégico"), ao mesmo tempo em que se ressalta $o$ caráter fluido, contingente $e$ contextual das identidades e identificações sexuais e de gênero.

Às vezes, teoria queer parece indicar não uma abordagem distintiva, mas uma referência maior, que englobaria um conjunto de concepções desnaturalizantes e politizadas sobre a sexualidade, o que não parece se distinguir muito de uma versão de 
"construcionismo radical", conforme a conhecida classificação de Carole Vance (1995). Dessa forma, ressalta-se que a sexualidade é um vetor de estratificação e opressão, que ela conta para a produção social das diferenças e das desigualdades. Essa ideia, que encontra uma formulação poderosa em um ensaio muito influente de Gayle Rubin (1984), costuma ser associada à teoria queer, embora tenha nítidas relações de continuidade com linhas da antropologia da sexualidade que se fazia no Brasil desde o final dos anos 1970 (Carrara e Simões, 2007). Com efeito, pode-se argumentar que esses problemas não estiveram fora do alcance das preocupações da antropologia com classificações e sistemas classificatórios, em termos da distinção entre as lógicas que articulam categorias e atribuições identitárias e os processos pelos quais indivíduos tornam-se sujeitos $e$ atores sociais, apropriando-se de - ou sendo levados a se reconhecer em determinadas identidades.

Levando tudo isso em conta, fica bastante difícil situar a abordagem queer como ruptura, tal como ela mesma muitas vezes se anuncia. Parece-nos que o termo extrai sua força pela conotação politicamente ampla de desestabilização das molduras socioculturais que enquadram categorias e identidades, como um "significante antinormativo" (De La Dehesa, 2010) de desafio ao heterossexismo ou à heteronormatividade. Não é raro, porém, que queer apareça como um meio de designar mais uma nova $e$ intrigante categoria identitária, como a serpente que engole a própria cauda.

\section{Conhecimento, ética, política}

Tendo iniciado este ensaio com considerações sobre disjunções e fraturas que levaram ao esboroamento da homossexualidade, é um tanto surpreendente constatarmos a permanência dos "homossexuais" ou da "homossexualidade" nas colaborações enviadas ao GT. Talvez essa permanência se deva, de um lado, a persistência do termo como categoria de autodefinição ou de atribuição identitária em determinados 
contextos etnográficos; de outro lado, os termos parecem conservar alguma força como descritores coletivos, especialmente quando os sujeitos são "homens", ou "homens que se relacionam afetivo-sexualmente com outros homens".

É também interessante o fato de expressões que emergem da crítica à essencialização de certas identidades reaparecerem elas mesmas como categorias identitárias (como "homoerótico" ou "queer"). E ainda o fato de certos acrônimos, como LGBT, que apontariam para espécies de federações de múltiplos coletivos transformarem-se em identidades individuais, como em "pessoa LGBT".

De certo modo, pensando mais particularmente nas "pessoas LGBT", podemos dizer que a explosão identitária a que atualmente assistimos no campo social espelha-se nos diferentes sujeitos que mobilizamos em nossas pesquisas. Em ambos os casos, temos uma notável superposição de diferentes deles sem que seja facilmente perceptível o solo comum que os acolhe. Assim, a um sujeito político múltiplo que sempre discute a base de sua aliança com esses seus "outros" parentes, parece corresponder um objeto de conhecimento também múltiplo - o que tem nos feito pensar sobre o quê, afinal, preencheria aqueles estreitos espaços brancos (e em branco) que separam uma letra (e um sujeito) da outra. ${ }^{9}$ Nesse sentido, as discussões mais profícuas do grupo se deram no sentido de pensar as complexas implicações entre sexualidade, corpo $e$ gênero em diferentes contextos sociais e históricos.

9 Talvez essa dificuldade possa ser ilustrada por um paralelo com a valorização da experiência nos estudos feministas, que requer um permanente trabalho de destruição da autoridade de um Outro opressor para determinar o que seja a experiência feminina, tal como sugere Strathern (2009:97-98): "O Outro nãofeminista é geralmente concebido como o 'patriarcado', $e$ as instituições $e$ pessoas que representam a dominação masculina são simplesmente, de maneira frequente, concretizadas pelo termo "homens'". Por mais simplificada que essa concepção pareça, de uma perspectiva antropológica, pode-se reconhecer que ela mantém um solo comum de ação política para o movimento feminista, no esforço de restaurar a subjetividade de um eu dominado pelo Outro. Parece muito mais complicado determinar o que poderia ser o Outro não LGBT. 
Mas o que interessa ressaltar nesse ponto é que todas as expressões acima arroladas foram utilizadas, pelo menos uma vez, para designar indivíduos sobre os quais o pesquisador fala ou que participaram de sua pesquisa, seja na figura do "informante" (expressão utilizada uma única vez), seja na mais referida figura do "ator" (9 menções) - que em um resumo aparece sugestivamente na expressão "atores da pesquisa" - $e$, principalmente na figura do "sujeito", dos "sujeitos da pesquisa", que, em alguns casos, aparecerão qualificados, como "sujeitos homo-orientados", "sujeitos políticos", "sujeitos que frequentam uma casa noturna "GLS", ou "sujeitos sexualizados e generificados de uma favela".

Assim, se "indivíduos" e "pessoas" participam das diferentes investigações, eles o fazem principalmente na posição de "atores" $e$ "sujeitos", sendo que alguns trabalhos se voltam para o processo de produção desses sujeitos. A menção a "sujeito" aparece 45 vezes em contraposição a de "pessoa" (12) e "indivíduo" (5). Definitivamente, parece que os antropólogos e antropólogas contemporâneos não têm mais "informantes". 10 Por outro lado, esperamos que nossa constante menção a "atores" $e$ "sujeitos" não indique apenas que encontramos uma espécie de fórmula mágica capaz de liberar nossa palavra (de acadêmicos $e$ pesquisadores) dos constrangimentos éticos e políticos que hoje perpassam a disciplina, instada a todo o momento a esclarecer o tipo de engajamento que mantém com aqueles sobre os quais tece o seu discurso. Ou seja, esperamos que não estejamos apenas incorporando um novo jargão acadêmico, eivado de novos "deslizes semânticos" "11, que mais dificulta do que facilita a árdua tarefa de enfrentar teórica e praticamente os delicados dilemas

\footnotetext{
${ }^{10} \mathrm{E}$, ressaltamos, não defendemos a manutenção desse termo ou expressão; especialmente no contexto brasileiro, em que "informante" significa, no jargão policial, o "X9" ou "o infiltrado", que passa sorrateiramente informações à polícia. Nessa acepção, o termo seria muito mais apropriado para designar os próprios antropólogos e antropólogas e não os "seus nativos".

11 Tomamos de empréstimo a expressão de Eunice Durham (2004).
} 
éticos que, nas pesquisas em ciências humanas e sociais, continuam não resolvidos no que diz respeito à relação entre sujeito (aquele que fala) e objeto (sobre quem se fala).

Como sabemos, mas talvez não seja inútil repetir, tais dilemas são ainda mais perturbadores na antropologia, disciplina que tem como uma de suas convenções fundadoras a ideia de que o melhor conhecimento sobre o "Outro" depende do estabelecimento de uma relação emocional, um rapport entre quem observa e quem é observado, quem fala e de quem se fala, quem escreve e sobre quem se escreve; afinal, entre quem é autor e quem às vezes não parece ocupar nem a posição de possivel leitor.

Uma forte corrente crítica, dentro da própria disciplina, questionou a posição de autoria fundada na pretensão objetivista de produzir um relato integrado que ocultaria o processo de afetação mútua e interlocução próprio do trabalho de campo. Sua aposta em experimentações narrativas capazes de criar uma situação ideal de autoria coletiva e produto compartilhado, porém, mostra-se muitas vezes vulnerável na própria base ética que a inspira. Afinal, a experiência dialogicamente produzida acaba geralmente submetida ao controle final do pesquisador sobre o texto e subordinada aos usos da disciplina. Enquanto o compromisso central da pesquisa acadêmica for satisfazer os padrões derivados do fazer científico, em que a interlocução privilegiada se estabelece por meio de construtos conceituais $e$ marcos teóricos avaliados pelos pares, dificilmente a relação com as pessoas pesquisadas deixará de ser assimétrica: elas podem até estar na plateia das sessões de defesa pública de teses $e$ dissertações ou nos encontros acadêmicos, como o próprio grupo de trabalho sobre sexualidade da ANPOCS, mas invariavelmente não têm assento nas bancas examinadoras ou nos comitês que selecionam as comunicações que serão efetivamente apresentadas. Sob esse aspecto, nem sempre existe entre 
antropólogos e nativos "interesses em comum aos quais possa servir este produto supostamente comum". ${ }^{12}$

Certamente a colaboração entre pesquisadores $e$ pesquisados é central para qualquer pesquisa antropológica baseada em trabalho de campo. Pesquisadores e pesquisados podem compartilhar interesses substanciais, em termos de vivências, compromissos pessoais, simpatias ou posições políticas. Podem inclusive negociar temas, questões e categorias. Nesse sentido, não há conhecimento desinteressado ou que não tome partido (Becker, 1977). O fundamental parece ser precisamente reconhecer que tais negociações e compromissos incorporam-se aos fatos e discursos produzidos, para não reinstaurar, em nome de alguma comunhão ética, qualquer ingenuidade objetivista. Igualmente crucial é reconhecer que se trata de perspectivas diferentes, que se influenciam e se apoiam, mas também podem divergir e disputar o direito de definir o que seja a "realidade" sobretudo em situações politicamente tão sensíveis como as que caracterizam as pesquisas sobre diversidade sexual e de gênero. ${ }^{13}$

\section{Referências bibliográficas}

AgUiÃo, Silvia. Fazer-se no Estado: uma etnografia sobre o processo de constituição dos "LGBT" como sujeitos de direitos no Brasil contemporâneo. Tese de Doutorado em Ciências Sociais. Campinas, IFCH-Unicamp, 2014.

Aquino, Luís Octavio Rodrigues. As derivas do desejo. Processos de construção, manutenção e manipulação de identidades lésbicas em

\footnotetext{
12 Tomamos de empréstimo a frase com que Strathern formula o escárnio que uma perspectiva feminista, profundamente imbuída de sensibilidade política em relação a interesses sociais diferentes e desiguais, dirige contra uma antropologia que persegue o ideal ético de autoria coletiva e produção em colaboração, em que supostamente "nenhuma voz é subsumida pelo Outro" (Strathern, 2009). Strathern refere-se aqui à tendência que se convencionou denominar de "pósmodernista" na antropologia norte-americana, a partir de reflexões distintas como as de Paul Rabinow (1977) e James Clifford (1998).
}

${ }^{13}$ Para uma reflexão nesse sentido, ver Carrara, 2013. 
um conjunto de mulheres em Porto Alegre. Dissertação de Mestrado em Antropologia Social. Porto Alegre, IFCH-UFRGS, 1992.

BECKER, Howard S. De que lado estamos? In: BECKER, Howard S. Uma teoria da ação coletiva. Rio de Janeiro, Zahar, 1977, pp.122-136.

BRASIL. Ministério da Saúde. Secretaria Especial dos Direitos Humanos. Conselho Nacional de Combate à Discriminação. Brasil Sem Homofobia: Programa de Combate à Violência e à Discriminação contra GLBT e Promoção da Cidadania Homossexual. Brasília, Ministério da Saúde, 2004.

BuTLER, Judith. Bodies that matter. New York/London, Routledge, 1993.

CARDOSO, Ruth. Aventuras de antropólogos em campo ou como escapar das armadilhas do método. In: CARDOSO, Ruth.Obra reunida. São Paulo, Mameluco, 2011 [1986], pp.210-220.

CARRARA, Sérgio. Négocier les frontières, négocier aux frontières: l'anthropologie et le processus de "citoyennisation" de l'homosexualité au Brésil. Brésil(s). Sciences humaines et sociales, 4, 2013, pp.103-123.

CARRARA, Sérgio e SimÕES, Júlio Assis. Sexualidade, cultura e política: a trajetória da identidade homossexual masculina na antropologia brasileira. cadernos pagu (28), Campinas-SP, Núcleo de Estudos de Gênero - Pagu/Unicamp, 2007, pp.65-99.

CLIFFORD, James. Trabalho de campo, reciprocidade e elaboração de textos etnográficos: o caso de Maurice Leenhardt. In: CLIFFORD, James. A experiência etnográfica. Antropologia e literatura no século XX. Rio de Janeiro, Editora da UFRJ, 1998 [1980], pp.227-251.

DE LA DEHESA, Rafael. Queering the public sphere in Mexico and Brazil. Durham/ London, Duke University Press, 2010.

DURHAM, Eunice. A pesquisa antropológica com populações urbanas. In: DuRHAM, Eunice.A dinâmica da cultura. São Paulo, Cosac Naify, 2004 [1986], pp.357-376.

FACCHINI, Regina. Sopa de letrinhas? Movimento homossexual e produção de identidades coletivas nos anos 90. Rio de Janeiro, Garamond, 2005. 
FaCChINI, Regina; Daniliauskas, Marcelo; PILON, Ana Cláudia. Políticas sexuais e produção de conhecimento sobre gênero $e$ (homo)sexualidades no Brasil. Revista de Ciências Sociais (44/1), Fortaleza, 2013, pp.161-193.

FouCAUlt, Michel. História da sexualidade I. A vontade de saber. Rio de Janeiro Graal, 2001 [1976].

FRY, Peter. Da hierarquia à igualdade: a construção histórica da homossexualidade no Brasil. In: FRY, Peter. Para inglês ver. Rio de Janeiro, Zahar, 1982a [1974], pp.87-115.

FRY, Peter. Homossexualidade masculina e cultos afro-brasileiros. In: FRY, Peter. Para inglês ver. Rio de Janeiro, Zahar, 1982b [1977], pp.54-86.

FRY, Peter e MACRAE, Edward. O que é homossexualidade. São Paulo, Brasiliense, 1983.

GuimarãES, Carmen Dora. O homossexual visto por entendidos. Rio de Janeiro, Garamond, 2004 [1977].

HeILBORN, Maria Luiza. Dois é par. Gênero e identidade sexual em contexto igualitário. Rio de Janeiro, Garamond, 2004 [1992].

LANDES, Ruth. A cidade das mulheres. Rio de Janeiro, Editora da UFRJ, 2002 [1947].

LEACOCK, Seth e LEACOCK, Ruth. Spirits of deep. A study of an AfroBrazilian cult. New York. Doubleday Natural History Press, 1972.

LOBERT, Rosemary. A palaura mágica. A vida cotidiana dos Dzi Croquettes. Campinas, Editora da Unicamp, 2010 [1979].

MACRAE, Edward. A construção da igualdade.Campinas, Editora da Unicamp, 1990.

MECCIA, Ernesto. Los últimos homosexuales. Sociología de la homosexualidad y la gaycidad. Buenos Aires, Gran Aldea Editores, 2011.

MotT, Luiz. Escravidão e homossexualidade. Trabalho apresentado no III Congresso Afro-Brasileiro. Recife, Fundação Joaquim Nabuco, 1982a.

MOTT, Luiz. Homossexualidade: uma variável esquecida pela demografia histórica. Os sodomitas no Brasil colonial. Trabalho apresentado no 
III Encontro da Associação Brasileira de Estudos Populacionais, Vitória, $1982 b$.

MuNIZ, Jacqueline. Mulher com mulher dá jacaré: uma abordagem antropológica da homossexualidade feminina. Dissertação de Mestrado em Antropologia Social. Rio de Janeiro, MN-UFRJ, 1992.

PARKER, Richard G. Corpos, prazeres e paixões: a cultura sexual no Brasil contemporâneo. Rio de Janeiro, Editora Best Seller, 1991 [1988].

PERLONGHER, Nestor. O negócio do michê: prostituição viril em São Paulo. São Paulo, Editora Brasiliense, 1987.

PORTINARI, Denise. O discurso da homossexualidade feminina. São Paulo, Brasiliense, 1989.

RABINOW, Paul. Reflections on fieldwork in Morocoo. Berkeley, University of California Press, 1977.

RIBEIRO, René. Cultos afro-brasileiros do Recife: um estudo de ajustamento social. Recife, Instituto Joaquim Nabuco de Pesquisas Sociais, 1978 [1969].

RUBIN, Gayle. Thinking sex: notes for a radical theory of the politics of sexuality. In: VANCE, Carole (org.). Pleasure and danger: exploring female sexuality. Boston, Routledge \& Keagan Paul, 1984, pp.267-319.

SiLVA, Hélio R. S. Travesti, a Invenção do Feminino. Rio de Janeiro, Relume-Dumará/ISER, 1993.

SILVA, José Fábio Barbosa da. Homossexualismo em São Paulo. Estudo de um grupo minoritário. In: GREEN, James e TRINDADE, Ronaldo (org.) Homossexualismo em São Paulo e outros escritos. São Paulo, Editora Unesp, 2005 [1958], pp.39-212.

SIMMEL, Georg. Sociabilidade, um exemplo de sociologia pura ou formal. In: Simmel: sociologia. São Paulo, Ática, 1983 [1917], pp.165-181.

SIMÕES, Júlio Assis e FACCHINI, Regina. Na trilha do arco-íris: do movimento homossexual ao LGBT. São Paulo, Editora Fundação Perseu Abramo, 2009.

STRATHERN, Marilyn. Uma relação incômoda: o caso do feminismo e da antropologia. Mediações, 14 (2), Londrina-PR, UEL, 2009[1987], pp.83-104. 
98 ensaio sobre sujeitos, temas e abordagens

VANCE, Carole, A antropologia redescobre a sexualidade: Um comentário teórico. Physis - Revista de Saúde Coletiva, 5 (1), Rio de Janeiro, IMS-UERJ, 1995, pp.7-31. 